\title{
HUBUNGAN KARAKTERISTIK SOSIAL EKONOMI PETANI DENGAN TINGKAT PENERAPAN TEKNOLOGI USAHATANI PADI SAWAH LAHAN RAWA LEBAK DI KECAMATAN SEKERNAN KABUPATEN MUARO JAMBI
}

\author{
Sari Novita ${ }^{1)}$, Denny Denmar ${ }^{2)}$ dan Tri Suratno ${ }^{2)}$ \\ ${ }^{1}$ Alumni Program Studi Agribisnis Fakultas Pertanian Universitas Jambi \\ ${ }^{2}$ Dosen Program Studi Agribisnis Fakultas Pertanian Universitas Jambi \\ Email: Nrara92@Yahoo.com
}

\begin{abstract}
This research aims to determine the relationship of socio-economic characteristics of farmers with a level of technology implementation paddy rice farming lowland swamp land in District Sekernan Muaro Jambi. This research was conducted in October and November 2014 in Sub Sekernan Muaro Jambi. Data collection consists of primary and secondary data. The population of farmers in Jambi District Sekernan Muaro consisting of two villages namely Causeway Village Pulai village of 145 farmers and 105 farmer until Sekernan of the overall population of 250 farmers. Using simple random sampling (simple random sampling). Samples taken are as much as $20 \%$ of the population in order to obtain 50 lowland rice farmers. To find out about the description of the relationship with the social and economic characteristics of paddy farming technology implementation lowland swamp land in the study area, tabulation of data processed and followed by a descriptive analysis using frequency distribution table, while to determine the relationship of socio-economic characteristics of farmers with a level of technology implementation swampy lowland rice farming using non-parametric statistical test Chi Square (2x2). According to Siegel (1997), chi square test. Results of this study indicate that there is a significant relationship between the experience to farm, land tenure and the availability of family labor and the level of implementation of lowland rice farming technology lowland swamp land in District Sekernan Muaro Jambi with a confidence level of 95\%, whereas at the level of age, formal education and non-formal education there is no significant relationship with the level of technology implementation paddy rice farming lowland swamp land in the district Sekernan Mauro Jambi Regency at level of 95\%.
\end{abstract}

Keywords: Socio economic Characteristics, Application Technology, Lowland Rice

\begin{abstract}
ABSTRAK
Penelitian ini bertujuan untuk mengetahui hubungan karakteristik sosial ekonomi petani dengan tingkat penerapan teknologi usahatani padi sawah lahan rawa lebak di Kecamatan Sekernan Kabupaten Muaro Jambi. Penelitian ini di laksanakan pada bulan Oktober sampai November 2014 di Kecamatan Sekernan Kabupaten Muaro Jambi. Pengumpulan data terdiri dari data primer dan sekunder. Populasi petani pada Kecamatan Sekernan Kabupaten Muaro Jambi yang terdiri dari dua Desa yaitu Desa Pematang Pulai sebanyak 145 petani dan Desa Sekernan sebanyak 105 petani sehingga populasi keseluruhan sebanyak 250 petani. Pengambilan sampel menggunakan acak sederhana (Simple Random Sampling). Sampel yang diambil adalah sebanyak $20 \%$ dari populasi sehingga diperoleh 50 petani padi sawah lebak. Untuk mengetahui tentang gambaran hubungan karakteristik sosial ekonomi dengan penerapan teknologi usahatani padi sawah lahan rawa lebak di daerah penelitian, data diolah secara tabulasi dan dilanjutkan dengan analisis deskriptif menggunakan tabel distribusi frekuensi, sementara untuk mengetahui hubungan karakteristik sosial ekonomi petani dengan tingkat penerapan teknologi usahatani padi sawah lebak menggunakan statistik non parametrik Uji Chi Square (2x2). Menurut Siegel (1997), uji chi square. Hasil penelitian ini menunjukkan bahwa terdapat hubungan yang signifikan antara
\end{abstract}


pengalaman berusahatani, penguasaan lahan dan ketersediaan tenaga kerja keluarga dan dengan tingkat penerapan teknologi usahatani padi sawah lahan rawa lebak di Kecamatan Sekernan Kabupaten Muaro Jambi dengan tingkat kepercayaan 95\%, sedangkan pada tingkat umur, pendidikan formal dan pendidikan non formal tidak terdapat hubungan yang signifikan dengan tingkat penerapan teknologi usahatani padi sawah lahan rawa lebak di Kecamatan Sekernan Kabupaten Mauro Jambi pada taraf kepercayaan $95 \%$.

\section{Kata Kunci: Karakteristik Sosial Ekonomi, Penerapan Teknologi, Padi Sawah PENDAHULUAN}

Provinsi Jambi merupakan salah satu daerah penghasil tanaman padi sawah yang cukup banyak dibudidayakan. Padi sawah dibudidayakan di Kabupaten atau Kota yang ada di Provinsi Jambi dengan jumlah 129.341 ha luas panen. Provinsi Jambi mempunyai potensi lahan rawa lebak yang dapat dikembangkan untuk pertanian seluas 40.521 ha sedangkan yang telah dimanfaatkan untuk persawahan lebak sekitar 21.402 ha, tersebar di Kabupaten Kerinci, Muaro Jambi, Batanghari, Tebo, Bungo, Kota Jambi, Sarolangun dan Tanjung Jabung Barat. Semenjak tahun 2003 pemerintah Indonesia telah memprogramkan pengembangan lahan rawa lebak di Provinsi Jambi seluas 24.15 ribu ha, yang beralokasi di Kabupaten Batanghari seluas 9.3 ribu ha Muaro Jambi 7.1 ribu ha. Kabupaten Muaro Jambi adalah salah satu Kabupaten dimana banyak petaninya mengusahakan usahatani padi lebak, sementara lahan rawa lebak yang ada umumnya produksi relatif rendah, oleh karena itu peluang peningkatan produksi yang dilakukan diharapkan tersedia namun pelaksanaannya oleh petani umumnya belum sesuai anjuran PPL/BPP.

Upaya peningkatan produksi padi lebak adalah mendukung ketahanan pangan pemda Kabupaten Muaro Jambi yang dilakukan dengan aktivitas intensifikasi penerapan teknologi baru. Teknologi usahatani padi lebak yang diusahakan petani di Kecamatan Sekernan masih belum mampu untuk meningkatkan produksi maupun dinamika usahatani padi lebak baik secara teknis fisik, agronomis dan finansial. Pada pelaksanaan usahatani padi lebak di Kecamatan Sekernan terdapat berbagai cara dalam adopsi inovasinya mulai dari yang tradisonal sampai yang modern, namun pada kenyataannya pelaksanaan usahatani padi lebak menggunakan cara yang tradisonal, sehingga para petani sulit untuk mengubah cara pelaksanaannya, baik dari segi cara pengolahan tanah sampai panen, dan ini menjadi budaya.

Kebiasan petani yang menggunakan cara pelaksanaan dalam berusahatani padi lebak yang tradisonal itu membuat para penyuluh sulit untuk mengubah pola fikir petani. Banyak faktor yang menyebabkan petani tidak mau mengubah cara pelaksanaannya untuk usahatani padi lebak, salah satu faktornya adalah faktor internal yang ada pada diri petani itu sendiri. Dimana faktor tersebut sangat mempengaruhi pelaksanaanya, baik dilihat dari kondisi umur petani, pengalaman petani, pendidikan petani, penguasaan lahan petani, ketersediaan tenaga kerja keluarga petani yang ikut mempengaruhi dalam meningkatkan pelaksanaan usahatani padi sawah lahan rawa lebak tersebut.

Untuk keberhasilan kegiatan usahatani khusunya usahatani padi sawah lahan rawa lebak maka penerapan teknologi usahatani padi sawah lahan rawa lebak merupakan syarat mutlak yang harus dipenuhi. Kondisi ini tidak terlepas dari latar belakang petani yang berkaitan dengan keadaan sosial ekonominya karena apabila petani itu ingin usahataninya memiliki produksi yang tinggi maka memerlukan teknologi yang tepat guna agar hasil produksinya akan meningkat. Adanya teknologi baru untuk usahatani padi sawah lahan rawa lebak yang anjurkan oleh pemerintah melalui PPL maka petani perlu untuk mengetahui dan memahami tentang teknologi baru tersebut agar mereka mampu dalam menerapkan teknologi baru. Apabila petani masih menggunakan cara yang tradisonal maka petani sangat sulit mengubah kebiasaannya, oleh karena itu keadaan sosial ekonomi petani dalam menerapkan teknologi sangat di perlukan. Cara pelaksanaan yang dianjurkan oleh pemerintah melalui PPL akan memberikan dampak positif bagi petani apabila petani itu memahami dan mau mengubah kebiasaanya 
tersebut. Petani itu berbeda jenis karakteristiknya, masing-masing petani mempunyai karakter sehingga untuk menggubah karakter tersebut sangat sulit perlu waktu yang lama untuk mengubahnya.

Penelitian ini bertujuan untuk mengetahui gambaran umum karakteristik sosial ekonomi petani padi sawah lahan rawa lebak di Kecamatan Sekernan yang kedua untuk mengetahui tingkat penerapan teknologi usahatani padi sawah lahan rawa lebak di Kecamatan Sekernan dan yang ketiga untuk mengetahui hubungan karakteristik sosial ekonomi petani dengan tingkat penerapan teknologi usahatani padi sawah lahan rawa lebak di Kecamatan Sekernan Kabupaten Muaro Jambi.

\section{METODE PENELITIAN}

Ruang lingkup Penelitian ini dilaksanakan di Kecamatan Sekernan Kabupaten Muaro Jambi Lokasi penelitian ini dipilih dengan sengaja (purposive) dengan pertimbangan bahwa Kecamatan Sekernan merupakan salah satu sentra produksi padi sawah lahan rawa lebak di Kabupaten Muaro Jambi. Pada Kecamatan Sekernan terdapat berbagai Desa/Kelurahan, di setiap Desa/Kelurahan ada 16 desa namun yang melaksanakan usahatani padi sawah terdapat 12 desa. Salah satu desa yang melaksanakan usahatani padi sawah yaitu desa Pematang Pulai dan Desa Sekernan. Objek yang dalam penelitian ini adalah petani padi sawah lahan rawa lebak Penelitian ini dilaksanakan dari bulan Oktober sampai November tahun 2014.

Data yang digunakan merupakan data primer yang diperoleh dari petani responden yang melakukan kegiatan usahatani padi sawah lahan rawa lebak. Data sekunder yang diperoleh dari instansi terkait seperti Badan Pusat Statistik Provinsi Jambi, Balai Pengkaji Teknologi Pertanian Provinsi Jambi, Badan Pusat Statistik Kabupaten Muaro Jambi, Dinas Pertanian Tanaman Pangan dan Hortikultura Kabupaten Muaro Jambi, Balai Penyuluhan Pertanian Kecamatan Sekernan dan hasil-hasil penelitian terdahulu. Jumlah petani sampel ditentukan dengan menggunakan kaidah Singarimbun, 2011 sebanyak 50 petani padi sawah lahan rawa lebak.

Analisis yang digunakan dalam penelitian ini menggunakan analisis kuantitatif yang dideskriftifkan.Pengumpulan data primer dilakukan dengan pengisian kuisioner dari petani responden. Selain itu juga dilakukan pengumpulan data sekunder melalui penelusuran internet dan dinas terkait dalam penelitian ini. Data yang terkumpul dari hasil penelitian diolah secara tabulasi, kemudian dianalisis secara kuantitatif dalam bentuk tabel-tabel. Untuk menghitung hubungan karakteristik sosial ekonomi petani dengan tingkat penerapan teknologi usahatani padi sawah lahan rawa lebak menggunakan rumus chi square koefesien kontingensi (2×2)Menurut Siegel (1997), uji Chi Square koefesien kontingensi (C) $2 \times 2$ dapat dihitung dengan ketentuan sebagai berikut :

Apabila sel berisi frekuensi $\geq 5$, maka rumus yang digunakan adalah sebagai berikut:

$$
x^{2}=\frac{N[(A D-B C)]^{2}}{(A+B)(C+D)(A+C)+(B+D)} \quad: d b=1
$$

Apabila sel berisi frekuensi ada yang $\leq 5$, digunakan rumus sebagai berikut :

$$
x^{2}=\frac{\left.N[(A D-B C)]-\frac{N}{2}\right]}{(A+B)(C+D)(A+C)+(B+D)} \quad: d b=1
$$

Nilai $X^{2}$ dengan derajat bebas satu $(\mathrm{db})=1$ pada tingkat kepercayaan $95 \%$ adalah 3,84 dalam pengujian nilai $X^{2}$ hitung dibandingkan dengan $X^{2}$ tabel dengan ketentuan sebagai berikut :

1. Terima $\mathrm{H}_{0}$, tolak $\mathrm{H}_{1}$ jika $\mathrm{X}^{2}$ hitung $\leq \mathrm{X}^{2}$ tabel berarti tidak terdapat hubungan signifikan karakteristik sosial ekonomipetani terhadap tingkat penerapan teknologi usahatani padi sawah lahan rawa lebak. 
2. Tolak $H_{0}$, terima $H_{1}$ jika $X^{2}$ hitung $\geq X^{2}$ tabel terdapat hubungan signifikan karakteristik sosial ekonomipetani terhadap tingkat penerapan teknologi usahatani padi sawah lahan rawa lebak.

Selanjutnya untuk mengukur derajat hubungan antara dua variabel digunakan koefesien kontingensi dan formulanya sebagai berikut :

$$
C_{\text {hit }}=\sqrt{\frac{\chi^{2}}{\chi^{2}+N}} \quad \text { dan } \quad C_{\text {maks }}=\sqrt{\frac{m-1}{m}}
$$

Dimana :

$X^{2}=x^{2}$ hitung

$\mathrm{N}=$ Jumlah Sampel

$\mathrm{m}=$ Jumlah kolom / baris uji chi-square

$\mathrm{C}=$ Koefesien Kontingensi

Dengan ketentuan sebagai berikut :

1. Derajat kecenderungan bernilai lemah bila nilai terletak antara $0-0,353$

2. Derajat kecenderungan digolongkan kuat apabila nilai terletak antara $0,353-0,707$

Setelah itu untuk mengukur keeratan hubungan digunakan formulasi sebagai berikut :

$$
r=\frac{C_{\text {hit }}}{C_{\text {maks }}}
$$

Adapun penguji hipotesis dilakukan dengan formulasi sebagai berikut :

dimana :

$$
t_{\text {hit }}=r \sqrt{\frac{N-2}{1-(r)^{2}}}
$$

$\mathrm{H}_{\mathrm{o}} ; \mathrm{r}=0$

$\mathrm{H}_{1} ; \mathrm{r} \neq 0$

Jika $\mathrm{t}_{\text {hit }}\left\{\leq t_{\text {tabel }}=(x=5 \% d b=N-2)\right\}$ terima $\mathrm{H}_{0}$

Jika $\mathrm{t}_{\text {hit }}\left\{\geq t_{\text {tabel }}=(x=5 \% d b=N-2)\right\}$ tolak $\mathrm{H}_{0}$

\section{HASIL DAN PEMBAHASAN}

\section{Karakteristik Sosial Ekonomi}

Bagian dari Karakteristik sosial ekonomi meliputi : Umur, tingkat pendidikan, pengalaman berusahatani, penguasaan lahan, ketersediaan tenaga kerja keluarga.

\section{Umur}

Menurut Margono (1978) dalam Anggraini (2005) mengatkan bahwa umur akan mempengaruhi kemampuan fisik dan cara berfikir petani. Umur petani adalah salah satu faktor yang berkaitan erat dengan kemampuan kerja dalam melaksanakan kegiatan usahatani, umur dapat dijadikan sebagai tolak ukur dalam melihat aktivitas seseorang dalam bekerja bilamana dengan kondisi umur yang masih produktif maka kemungkinan besar seseorang dapat bekerja dengan baik dan maksimal. Menurut Hernanto (2009) Usia produktif biasanya berada pada 15-45 tahun, dalam penelitian ini umur yang akan dilihat adalah umur yang produktif dan non produktif untuk lebih jelasnya lihat pada Tabel 1.

Tabel 1. Distribusi Frekuensi Responden Berdasarkan Karakteristik Sosial Ekonomi Petani Pada Tingkat Umur di Kecamatan Sekernan Kabupaten Muaro Jambi Tahun 2014

\begin{tabular}{ccc}
\hline Umur (Tahun) & Frekuensi & Persentase (\%) \\
\hline Tinggi ( $\geq 43$ Tahun) & 24 & 48 \\
Rendah ( $\leq 43$ Tahun) & 26 & 52 \\
\hline Jumlah & $\mathbf{5 0}$ & $\mathbf{1 0 0}$ \\
\hline
\end{tabular}


Berdasarkan Tabel 1 menunjukkan bahwa frekuensi umur yang dimiliki oleh petani di daerah penelitian tergolong tergolong umur yang produktif atau rendah dengan persentase sebesar 52\%. Umur yang produktif terbilang bagus untuk meningkatkan produksi usahataninya dengan banyaknya umur yang produktif maka petani akan lebih mudah memahami tentang hal-hal baru dalam usahatani padi sawah. Dengan umur yang produktif yang dikatakan rendah akan membuat petani ingin mencari tahu hal hal baru.

\section{Tingkat Pendidikan}

Tingkat pendidikan biasanya diukur dengan tingkat pendidikan formal yang pernah ditempuh dimana tingkat pendidikan dapat diperoleh dari bangku sekolah sedangkan pendidikan non formal adalah pengetahuan yang diperoleh tanpa melalui sekolah yaitu melalui kursus-kursus. Menurut Kartasapoetra (1991) Penyuluhan merupakan sistem pendidikan yang bersifat non formal atau sistem pendidikan diluar sistem persekolahan. Petani harus aktif dalam mengikuti penyuluhan sehingga adopsi teknologi akan meluas dan berkembang.Dalam penelitian ini tingkat pendidikan yang ukur adalah tingkat pendidikan formal dan non formal dalam lebih jelasnya lihat pada Tabel 2.

Tabel 2. Distribusi Frekuensi Responden Berdasarkan Karakteristik Sosial Ekonomi Petani Pada Pendidikan Formal di Kecamatan Sekernan Kabupaten Muaro Jambi Tahun 2014

\begin{tabular}{ccc}
\hline Tingkat Pendidikan & Frekuensi & Persentase (\%) \\
\hline Tinggi $(>$ SLTA $)$ & 8 & 16 \\
Rendah $(\leq$ SLTA $)$ & 14 & 84 \\
\hline Jumlah & $\mathbf{5 0}$ & $\mathbf{1 0 0}$ \\
\hline
\end{tabular}

Berdasarkan Tabel 2 menunjukkan bahwa frekuensi pada pendidikan formal di daerah penelitian tergolong rendah dengan persentase sebesar $84 \%$. Pada penelitian ini terdapat tingkat pendidikan yang rendah walaupun pendidikan petani tergolong rendah namun petani sudah cukup mampu dalam menerapkan teknologi baru dalam usahatani padi sawah lebak, penelitian ini menunjukkan bahwa tingkat pendidikan tidak begitu mempengaruhi dalam menerapkan teknologi baru, karena jika petani mau menerapkan teknologi baru tidak memandang dari segi pendidikan, tetapi apa bila petani memiliki pendidikan tinggi mempermudah dalam memberikan informasi.

Tabel 3. Distribusi Frekuensi Responden Berdasarkan Karakteristik Sosial Ekonomi Petani Pada Pendidikan Non Formal di Kecamatan Sekernan Kabupaten Muaro Jambi Tahun 2014

\begin{tabular}{ccc}
\hline Tingkat Pendidikan & Frekuensi & Persentase (\%) \\
\hline Tinggi $(\geq 10)$ & 37 & 74 \\
Rendah $(\leq 10)$ & 13 & 26 \\
\hline Jumlah & $\mathbf{5 0}$ & $\mathbf{1 0 0}$ \\
\hline
\end{tabular}

Berdasarkan Tabel 3 menunjukkan bahwa frekuensi pada pendidikan non formal di daerah penelitian tergolong tinggi dengan persentase sebesar $74 \%$. Pendidikan non formal sangat membantu dalam menerapkan teknologi baru karena semakin tingggi pendidikan non formal maka petani lebih memahami teknologi baru akan semakin mudah karena petani sudah mengikuti kegiatan yang dilakukan oleh penyuluh.

\section{Pengalaman Berusahatani}

Menurut Mardikanto dan Sitarni (1982) dalam Anggraini (2005) menyebutkan bahwa petani pada umumnya melaksanakan kegiatan usahataninya berdasarkan pengalaman praktek yang telah 
diwariskan oleh nenek moyang secara turun temurun sebagai suatu kebiasaan hidup sehingga mereka akan lebih berhati-hati terhadap hal-hal baru. Menurut Soekartawi (2005) mengatakan bahwa salah satu yang harus dimiliki oleh petani dalam mencapai keberhasilan pelaksanaan adopsi inovasi adalah peranan pengalaman. Pada penelitian ini tingkat pengalaman berusahatani diukur dari jawaban petani dalam skor pada kuisoner dalam mengusahakan usahatani padi sawah lebak untuk lebih jelasnya lihat Tabel 4.

Tabel 4. Distribusi Frekuensi Responden Berdasarkan Karakteristik Sosial Ekonomi Petani Pada Tingkat Pengalaman Berusahatani di Kecamatan Sekernan Kabupaten Muaro Jambi Tahun 2014

\begin{tabular}{ccc}
\hline Pengalaman Berusahatani & Frekuensi & Persentase (\%) \\
\hline Tinggi $(\geq 15)$ & 31 & 62 \\
Rendah $(\leq 15)$ & 19 & 38 \\
\hline Jumlah & $\mathbf{5 0}$ & $\mathbf{1 0 0}$ \\
\hline
\end{tabular}

Berdasarkan Tabel 4 menunjukkan bahwa frekuensi yang di dapat pada pengalaman berusahatani yang dilakukan di daerah penelitian tergolong tinggi dengan persentase $62 \%$. Pengalaman petani yang tergolong tinggi membuat petani untuk menerapakan teknologi baru karena petani akan lebih meningkatkan dalam menerima inovasi baru. Apabila pengalaman petani sudah mengikuti anjuran dari PPL, itu berarti akan mudah dalam menerapkan teknologi usahataninya

\section{Penguasaan Lahan}

Menurut Kartasapoetra (1991) petani yang mempunyai lahan pertanian yang lebih luas dari petani yang rata-rata mempunyai sebidang lahan sempit (0,5-2,5 ha) lebih berani untuk menanggung resiko, petani ini berani menghadapi kegagalan dari setiap percobaannya. Dalam penelitian ini luas lahan yang diusahakan oleh petani dengan melihat jawaban dari skor pada kuisioner untuk usahatani padi sawah untuk lebih jelas lihat pada Tabel 5.

Tabel 5. Distribusi Frekuensi Responden Berdasarkan Karakteristik Sosial Ekonomi Petani Pada Penguasaan Lahan di Kecamatan Sekernan Kabupaten Muaro Jambi Tahun 2014

\begin{tabular}{ccc}
\hline Penguasaan Lahan & Frekuensi & Persentase (\%) \\
\hline Tinggi $(\geq 11)$ & 36 & 72 \\
Rendah $(\leq 11)$ & 14 & 28 \\
\hline Jumlah & $\mathbf{5 0}$ & $\mathbf{1 0 0}$ \\
\hline
\end{tabular}

Berdasarkan Tabel 5 menunjukkan bahwa frekuensi pada penguasaan lahan yang dilakukan oleh petani di daerah penelitian tergolong tinggi dengan persentase $72 \%$. Artinya petani di daerah penelitian sudah menguasaai lahanoleh karena itu petani akan lebih mudah dalam menerapakan teknologi baru karena mempertimbangkan resiko kegagalan yang sedikit jika petani menguasai lahan yang di usahakan.

\section{Ketersediaan Tenaga Kerja Keluarga}

Ketersedian tenaga kerja keluarga berdampak negatif terhadap kemajuan usahatani apabila anggota keluarga tersebut tidak menyumbangkan tenaganya. Bagi anggota keluarga yang menganggur hanya akan menambah beban bagi keluarga. Jika semakin banyak anggota keluarga yang menyumbangkan tenaganya maka semakin berdampak positif bagi pelaksanaan usahataninya.Dalam penelitian ini ketersediaan tenaga kerja keluarga dilihat dari melihat jawaban skor pada kuisioner untuk lebih jelasnya lihat Tabel 6 . 
Tabel 6. Distribusi Frekuensi Responden Berdasarkan Karakteristik Sosial Ekonomi Petani Pada Ketersediaan Tenaga Kerja Keluarga di Kecamatan Sekernan Kabupaten Muaro Jambi Tahun 2014

\begin{tabular}{ccc}
\hline Ketersediaan Tenaga Kerja Keluarga & Frekuensi & Persentase (\%) \\
\hline Tinggi $(\geq 6)$ & 28 & 56 \\
Rendah $(\leq 6)$ & 22 & 44 \\
\hline Jumlah & $\mathbf{5 0}$ & $\mathbf{1 0 0}$ \\
\hline
\end{tabular}

Berdasarkan Tabel 6 menunjukkan bahwa frekuensi ketersediaan tenaga kerja keluarga tergolong tinggi dengan persentase sebesar $56 \%$. Artinya pada daerah penelitian terdapat ketersediaan tenaga kerja keluarga yang tinggi sehingga dalam membantu untuk berusahatani akan semakin banyak dan mudah karena ketersediaan tenaga kerja dalam keluraga berdampak positif.

\section{Penerapan Teknologi Usahatani Padi Sawah Lebak}

Penerapan teknologi merupakan salah satu hal yang berguna bagi petani untuk meningkatkan produksi usahatani terutama pada komoditi padi sawah lebak.Teknologi yang dimaksud dalam penelitian ini adalah penerapan yang dianjurkan pemerintah melalui PPL.Teknologi ini merupakan teknologi dalam budidaya tanaman yang berperan penting dalam meningkatkan produksi padi sawah lebak dalam beberapa tahun terakhir ini. Teknologi ini merupakan suatu teknologi yang inovatif dan dinamis yang bertujuan untuk meningkatkan produksi petani melalui beberapa komponen.

Untuk mengetahui klasifikasi tingkat penerapan teknologi padi sawah lebak di daerah penelitian dapat dilihat pada penjelasan dibawah ini.

\section{Penyiapan Lahan}

Tabel 7. Distribusi Frekuensi Responden Berdasarkan Klasifikasi Penerapan Teknologi Usahatani Padi Sawah Lebak Pada Penyiapan Lahan di Kecamatan Sekernan Kabupaten Muaro Jambi Tahun 2014

\begin{tabular}{ccc}
\hline Penyiapan Lahan & Frekuensi & Persentase (\%) \\
\hline Tinggi (11-15) & 4 & 8 \\
Rendah (5-10) & 46 & 92 \\
\hline Jumlah & $\mathbf{5 0}$ & $\mathbf{1 0 0}$ \\
\hline
\end{tabular}

Berdasarkan Tabel 7 memperlihatkan bahwa pada penyiapan lahan terutama terhadap pengolahan tanah masih rendah sebesar 92\%. Petani yang menerapkan penyiapan lahan pada pengolahan tanah yang sesuai anjuran hanya sebesar $8 \%$. Berdasarkan survai di Kecamatan Sekernan ini lebih relatif tidak melakukan pengolahan lahan atau menerapkan sistem TOT (Tanpa Olah Tanah). Alasan petani menerapkan system TOT karena kondisi lahan yang masih subur.

\section{Varietas Unggul}

Tabel 8. Distribusi Frekuensi Responden Berdasarkan Klasifikasi Penerapan Teknologi Usahatani Padi Sawah Lebak Pada Penggunaan Varietas Unggul di Kecamatan Sekernan Kabupaten Muaro Jambi Tahun 2014

\begin{tabular}{ccc}
\hline Varietas Unggul & Frekuensi & Persentase (\%) \\
\hline Tinggi (8-12) & 46 & 92 \\
Rendah (4-7) & 4 & 8 \\
\hline Jumlah & $\mathbf{5 0}$ & $\mathbf{1 0 0}$ \\
\hline
\end{tabular}

Berdasarkan Tabel 8 memperlihatkan bahwa penerapan teknologi padi sawah lebak pada penggunaan benih unggul yang dilakukan oleh petani tergolong tinggi sebesar $92 \%$. Hal ini dikarenakan 
petani selalu mendapatkan bantuan benih dari pemerintah melalui PPL. Berdasarkan survai benih yang digunakan oleh petani adalah benih yang bervarietas ciherang, varietas ciherang digunakan karena cocok untuk daerah penelitian dimana varietas ciherang tahan akan genangan air, kekeringan, mampu berkompetisi dengan gulma dan mempunyai akar yang kuat.

Persemaian

Tabel 9. Distribusi Frekuensi Responden Berdasarkan Klasifikasi Penerapan Teknologi Usahatani Padi Sawah Lebak Pada Persemaian di Kecamatan Sekernan Kabupaten Muaro Jambi Tahun 2014

\begin{tabular}{ccc}
\hline Persemaian & Frekuensi & Persentase (\%) \\
\hline Tinggi (12-18) & 0 & 0 \\
Rendah (6-11) & 50 & 100 \\
\hline Jumlah & $\mathbf{5 0}$ & $\mathbf{1 0 0}$ \\
\hline
\end{tabular}

Berdasarkan Tabel 9 menunjukan bahwa pada penerapan teknologi padi sawah pada persemaian yang dilakukan oleh petani tergolong rendah sebesar $100 \%$. Semua petani yang ada di daerah penelitian tidak melakukan persemaian sesuai anjuran.

\section{Cara dan Tata Tanam}

Tabel 10. Distribusi Frekuensi Responden Berdasarkan Klasifikasi Penerapan Teknologi Usahatani Padi Sawah Lebak Pada Cara dan Tata Tanam di Kecamatan Sekernan Kabupaten Muaro Jambi Tahun 2014

\begin{tabular}{ccc}
\hline Cara dan Tata Tanam & Frekuensi & Persentase (\%) \\
\hline Tinggi (8-12) & 50 & 100 \\
Rendah (4-7) & 0 & 0 \\
\hline Jumlah & $\mathbf{5 0}$ & $\mathbf{1 0 0}$ \\
\hline
\end{tabular}

Berdasarkan Tabel 10 menunjukan bahwa pada penerapan teknologi padi sawah lebak pada cara dan tata tanam yang dilakukan oleh petani tergolong tinggi sebesar $100 \%$. Semua petani di daerah penelitian melakukan cara dan tata tanam sesuai anjuran, karena petani sudah mulai mau melakukan perubahan terhadap cara dan tata tanam yang baru. Cara dan tata tanam yang dilakukan adalah sistim jejar legowo karena petani mengakui keunggulan jejar legowo memudahkan dalam mengatasi gulma.

Pengelolaan Air

Tabel 11. Distribusi Frekuensi Responden Berdasarkan Klasifikasi Penerapan Teknologi Usahatani Padi Sawah Lebak Pada Pengelolaan Air di Kecamatan Sekernan Kabupaten Muaro Jambi Tahun 2014

\begin{tabular}{ccc}
\hline Pengelolaan Air & Frekuensi & Persentase (\%) \\
\hline Tinggi (6-9) & 36 & 72 \\
Rendah (3-5) & 14 & 28 \\
\hline Jumlah & $\mathbf{5 0}$ & $\mathbf{1 0 0}$ \\
\hline
\end{tabular}

Berdasarkan Tabel 11 menunjukkan bahwa tingkat penerapan teknologi pegelolaan air yang dilakukan oleh petani tergolong tinggi sebesar $72 \%$. Artinya bahwa petani di daerah penelitian benarbenar melakukan pengelolaan air agar budidaya padi sawah lebak berhasil. Pada daerah penelitian terdapat pintu air yang mengatur penggunaan air oleh petani. Pintu air ini berfungsi untuk mengeluarkan air dari areal persawahan. Berdasarkan penelitian dalam melakukan pengelolaan air petani membuat pematang yang berfungsi untuk menahan air dan mambuat saluran atau kemilir disekeliling petakan. 
Pemupukan

Tabel 12. Distribusi Frekuensi Responden Berdasarkan Klasifikasi Penerapan Teknologi Usahatani Padi Sawah Lebak Pada Pemupukan di Kecamatan Sekernan Kabupaten Muaro Jambi Tahun 2014

\begin{tabular}{ccc}
\hline Pemupukan & Frekuensi & Persentase (\%) \\
\hline Tinggi (5-6) & 25 & 50 \\
Rendah (2-4) & 25 & 50 \\
\hline Jumlah & $\mathbf{5 0}$ & $\mathbf{1 0 0}$ \\
\hline
\end{tabular}

Berdasarkan Tabel 12 menunjukkan bahwa pada penerapan teknologi pemupukan padi sawah lebak seimbang antara yang tinggi dan rendah sebesar $50 \%$. Berdasarkan dilapangan sebagian petani melakukan pemupukan walaupun belum sesuai yang di anjurkan karena petani mengatakan bahwa menggunakan pupuk harus melihat kondisi tanah pada lahan sawah, jika sudah subur hanya perlu sedikit pemupukan jika kondisi tanah kering maka perlu dilakukan pemupukan yang sesuai kebutuhan.

\section{Pengendalian Gulma}

Tabel 13. Distribusi Frekuensi Responden Berdasarkan Klasifikasi Penerapan Teknologi Usahatani Padi Sawah Lebak Pada Pengendalian Gulma di Kecamatan Sekernan Kabupaten Muaro Jambi Tahun 2014

\begin{tabular}{ccc}
\hline Pengendalian Gulma & Frekuensi & Persentase (\%) \\
\hline Tinggi (5-6) & 2 & 4 \\
Rendah (2-4) & 48 & 96 \\
\hline Jumlah & $\mathbf{5 0}$ & $\mathbf{1 0 0}$
\end{tabular}

Berdasarkan Tabel 13 menunjukkan bahwa tingkat penerapan teknologi pada pengendalian gulma padi sawah lebak tergolong rendah dengan persentase $96 \%$. Hasil survai bahwa petani melakukan pengendalian gulma secara mekanis dan kimiawi. Petani melakukan pengendalian gulma secara mekanis dengan cara gulma dicabut dan dimatikan karena lahan padi sawah di daerah penelitian tergolong subur akan gulma.

\section{Pengendalian Hama dan Penyakit}

Tabel 14. Distribusi Frekuensi Responden Berdasarkan Klasifikasi Penerapan Teknologi Usahatani Padi Sawah Lebak Pada Pengendalian Hama dan Penyakit di Kecamatan Sekernan Kabupaten Muaro Jambi Tahun 2014

\begin{tabular}{ccc}
\hline Pengendalian Hama dan Penyakit & Frekuensi & Persentase (\%) \\
\hline Tinggi (8-12) & 3 & 6 \\
Rendah (4-7) & 47 & 94 \\
\hline Jumlah & $\mathbf{5 0}$ & $\mathbf{1 0 0}$ \\
\hline
\end{tabular}

Berdasarkan Tabel 14 menunjukkan bahwa pada penerapan teknologi dalam pengendalian hama dan penyakit yang dilakukan oleh petani tergolong rendah sebesar $94 \%$, pengendalian hama dan penyakit tidak sesuai anjuran, petani hanya memberi rondentisida dalam melakukan pengendalian hama dan panyakit. Kurangnya pantauan dari PPL sehingga petani tidak begitu peduli dengan pengendalian hama dan penyakit. 
Panen dan Pasca Panen

Tabel 15. Distribusi Frekuensi Responden Berdasarkan Klasifikasi Penerapan Teknologi Usahatani Padi Sawah Lebak Pada Panen dan Pasca Panen di Kecamatan Sekernan Kabupaten Muaro Jambi Tahun 2014

\begin{tabular}{ccc}
\hline Panen dan Pasca Panen & Frekuensi & Persentase (\%) \\
\hline Tinggi (8-12) & 39 & 78 \\
Rendah (4-7) & 11 & 22 \\
\hline Jumlah & $\mathbf{5 0}$ & $\mathbf{1 0 0}$ \\
\hline
\end{tabular}

Berdasarakan Tabel 15 menunjukkan bahwa penerapan teknologi pada panen dan pasca panen yang dilakukan oleh petani tergolong tinggi sebesar 78\%. Berdasarkan survai di daerah penelitian petani sudah meningkatkan cara dalam pemanenan, pada daerah penelitian petani sudah mulai menggunkan alat yang modern dulu menggunakan ani-ani sekarang sudah berubah menjadi sabit dan mereka juga menggunakan mesin perontok padi sehingga waktu yang diperlukan tidak terlalu lama. Setelah melakukan perontokan petani segera melakukan penjemuran padi untuk menghindari tumbuhnya kecambah.

Tabel 16. Distribusi Frekuensi Responden Berdasarkan Nilai Penerapan Teknologi Usahatani Padi Sawah Lebak di Kecamatan Sekernan Kabupaten Muaro Jambi Tahun 2014

\begin{tabular}{ccc}
\hline Penerapan Teknologi Usahatani Padi Sawah lebak & Frekuensi & Persentase (\%) \\
\hline Tinggi $(>71)$ & 28 & 56 \\
Rendah $(<71)$ & 22 & 44 \\
\hline Jumlah & $\mathbf{5 0}$ & $\mathbf{1 0 0}$ \\
\hline
\end{tabular}

Berdasarkan Tabel 16 menunjukkan bahwa penerapan teknologi yang telah diterapkan oleh petani di Kecamatan Sekernan Kabupaten Muaro Jambi tergolong tinggi yaitu dengan persentase nilai sebesar $56 \%$. Artinya bahwa petani di Kecamatan Sekernan telah menerapkan teknologi padi sawah lebak sesuai anjuran yang dipelajari dari PPL.

Hal sebaliknya diungkapkan oleh Waluyo (2004) dalam penelitiannya bahwa teknologi usahatani padi yang diintroduksikan kepada petani sebagian komponen dapat diterapkan oleh petani, namun perlu ditingkatkan lagi dalam skala yang lebih luas. Penggunaan padi varietas unggul dalam sistem usahatani introduksi mempunyai prospek yang baik untuk dikembangkan oleh petani di rawa lebak

\section{Hubungan Karakteristik Sosial Ekonomi Petani Dengan Tingkat Penerapan Teknologi Usahatani Padi Sawah Lebak}

Berikut ini adalah hasil nilai hubungan karakteristik sosial ekonomi petani dengan tingkat penerapan teknologi usahatani padi sawah lebak di daerah penelitian.

Tabel 17. Rekapitulasi Nilai Hubungan Karaktersitik Sosial Ekonomi Petani Dengan Tingkat Penerapan Teknologi Usahatani Padi Sawah Lebak di Kecamatan Sekernan Kabupaten Muaro Jambi Tahun 2014

\begin{tabular}{ccccccc}
\hline No & Karakteristik Sosial Ekonomi & $\mathbf{X}^{2}$ & $\mathbf{X}_{\text {Tabel }}$ & $\mathbf{t}_{\text {Hitung }}$ & $\mathbf{T}_{\text {Tabel }}$ & $\begin{array}{c}\text { Signifikan } \\
\text { (Kepercayaan } \\
\text { 95\%) }\end{array}$ \\
\hline 1 & Umur & & & & & NS \\
2 & Tingkat Pendidikan & 2,99 & 3,841 & 2,506 & 2,011 & - \\
\hline
\end{tabular}




\begin{tabular}{ccccccc}
\hline & Pendidikan Non Formal & 2,18 & 3,841 & 15,197 & 2.011 & NS \\
3 & Pengalaman Berusahatani & 4,40 & 3,841 & 2,933 & 2.011 & SS \\
4 & Penguasaan Lahan & 6,82 & 3,841 & 3,895 & 2.011 & SS \\
5 & Ketersediaan Tenaga Kerja & 10,05 & 3,841 & 4,217 & 2.011 & SS \\
$\quad$ Keluarga & & & & & \\
\hline
\end{tabular}

\section{Keterangan : SS= Signifikan \\ NS= Non Signifikan}

Berdasarkan Tabel 17 memperlihatkan bahwa nilai yang diperoleh melalui perhitungan dengan menggunakan uji statistik non parametrik chi square memperlihatkan bahwa terdapat hubungan yang signifikan antara pengalaman berusahatani, penguasaan lahan, ketersediaan tenaga kerja dengan tingkat penerapan teknologi usahatani padi sawah lebak di Kecamatan Sekernan Kabupaten Muaro Jambi pada tahun 2014 dengan tingkat kepercayaan 95\%. Sedangkan pada tingkat umur, pendidkan formal dan pendidikan non formal tidak berhubungan dengan tingkat penerapan teknologi usahatani padi sawah lebak di Kecamatan Sekernan Kabupaten Muaro Jambi pada tahun 2014 dengan tingkat kepercayaan $95 \%$.

Hasil penelitian ini dapat mendukung pernyataan dari (choirutunnisa, (2008) membahas mengenai bahwa $99 \%$ hubungan yang sangat signifikan antara umur, pendidikan formal dan non formal dan $95 \%$ tingkat kepercayaan luas penguasaan lahan, pendapatan dan pengalaman dengan model pengelolaan tanaman terpadu padi sawah.

\section{KESIMPULAN}

Berdasarkan hasil penelitian terdapat hubungan yang signifikan antara pengalaman berusahatani, penguasaan lahan, ketersediaan tenaga kerja keluarga dengan tingkat penerapan teknologi usahatani pada sawah lebak pada taraf kepercayaan 95\%. Sedangkan pada tingkat umur, tingkat pendidikan formal dan pendidkan non formal tidak terdapat hubungan yang signifikan dengan tingkat penerapan teknologi usahatani pada sawah lebak pada taraf kepercayaan $95 \%$.

\section{UCAPAN TERIMA KASIH}

Pada kesempatan ini penulis mengucapkan terima kasih kepada Camat Sekernan, Kepala Desa Pematang Pulai, Kepala Desa Sekernan, Ketua Kelompok Mekar Sari, Ketua Kelompok Karya Baru dan PPL Desa Pematang Pulai dan Desa Sekernan yang memfasilitasi pelaksanaan penelitian dilapangan.

\section{DAFTAR PUSTAKA}

Anggraini, Dian. 2005. Karakteristik dan alokasi waktu kerja wanita tani di Kecamatan Jambi Selatan Kota Jambi. Fakultas Pertanian Universitas Jambi, Jambi (Tidak di Publikasikan).

Choirutunnisa. 2008. Hubungan Karakteristik Sosial Ekonomi Petani Dengan Tingkat Penerpan Model Pengelolaan Tanaman Terpadu Padi Sawah Di Desa Joho Kecamatan Mojolaban Kabupaten Sukoharjo. Universitas Sebelas Maret, Surakarta. 
Hernanto, F. 2009. Ilmu Usahatani. Penebar Swadaya, Jakarta. .1998. Ilmu Usahatani. Penebar Swadaya, Jakarta.

Kartasapoetra. 1991. Teknologi Penyuluhan Pertanian. Bumi Aksara, Jakarta.

Singarimbun dan Effendi. 2011. Metode Penelitian Survai. LP3ES, Jakarta.

Soekanto, S. 1986. Sosiologi Suatu Pengantar. Rajawali Press, Jakarta.

Soekartawi. 2005. Prinsip Dasar Komunikasi Pertanian. Universitas Indonesia, Malang.

Siegel, Sidney. 1997. Statistik Non Parametrik. Gramedia Utama, Jakarta.

Waluyo, 2004. Teknologi Usahatani Di Lahan Lebak (Studi Kasus: Desa Batu Ampar, Kabupaten. OKI, Sumatera Selatan). Di unduh dari journal.ipb.ac.id/index.php/jupe/article/download/2097/1128. (diakses 05 Februari 2015). 